6. National Occupational Health and Safety Commission. Workrelated traumatic fatalities in Australia, 1989 to 1992Agriculture industry. Canberra: Commonwealth of Australia, 1998.

7. Franklin R, Mitchell R, Driscoll T, Fragar L. Farm related fatalities 1989-1992. Moree: National Farm Injury Data Centre, Australian Centre for Agricultural Health and Safety, 2000.

8. Fragar LJ, Franklin R. The health and safety of Australia's farming community. Moree: National Farm Injury Data Centre, Australian Centre for Agricultural Health and Safety, 2000.

9. Australian Centre for Agricultural Health and Safety. Road fatalities in the farming community-Information sheet. Canberra: Australian Transport Safety Bureau, 1999.

10. Page A, Fragar LJ. Suicide in Australian farming 19881997. In press.

11. Cerhan JR, Cantor KP, Williamson K, Lynch CF, Torner JC, Brumeister LF. Cancer Causes among Iowa farmers: recent results, time trends and lifestyle factors. Cancer Causes Control May 1998; 9(3): 311-9.

12. Blair A, Zahm SH. Agricultural exposures and cancer. Environ Health Perspect November 1995; 103 (Suppl 8): 205-8.

13. Heffernan JB. 1991. A rural sociologist's perspective. Surgeon general's Conference on Agricultural Safety and Health April 30-May 3, 1991. Des Moines, Iowa: National Institute for Occupational Safety and Health, 1991.

14. Trigg H. Regional rural revival-factors affecting the viability and prosperity of rural towns. Outlook 98: Proceedings of the National Agricultural and Resources Outlook Conference, Canberra, 3-5 February 1998. Agriculture 1998; 2: 155-60.

15. Department of Health and Aged Care. National Environmental Health Strategy. Canberra: Commonwealth of Australia, 1999.

16. Australian Bureau of Statistics. Agriculture Australia. Canberra: Australian Bureau of Statistics, 1999.

\title{
BUILDING CAPACITY IN RURAL HEALTH
}

\section{David Lyle}

Department of Rural Health

University of Sydney, Broken Hill

\section{Charles Kerr}

Department of Public Health and Community Medicine University of Sydney, Camperdown

Capacity building to increase health gains in defined populations is not a new concept. Nevertheless, as interpreted by Penny Hawe and her colleagues, ${ }^{1}$ and as developed operationally by the NSW Department of Health, ${ }^{2,3}$ enhancing regional capacity to deal more effectively with the health needs and demands of people living in rural and remote Australia offers real promise as a useful approach for improvement. Essentially, capacity building in public health involves:

- delivering high quality services;

- responses to specified situations or problems;

- developing the regional system to solve new problems and respond to unfamiliar circumstances.

This article describes what effective and sustainable infrastructure is needed to achieve this capacity, with an emphasis on recent initiatives in the education and vocational training of rural health professionals.

\section{THE HEALTH NEEDS OF RURAL AUSTRALIANS}

Rural health has been on the political agenda for some time now. ${ }^{4}$ The poorer health status of rural residents has been well documented; and in particular, that of Aboriginal and Torres Strait Islander peoples. ${ }^{5}$

Around 30 per cent of the Australian population lives outside the metropolitan centres in communities that are geographically distinct and dispersed, ranging from major regional centres, country towns, to small isolated settlements and pastoral stations. The prominence of regional centres in economic and infrastructure terms is somewhat offset by the fact that most ( $>85$ per cent) rural and remote communities are small in size with populations ranging between 200-5,000. Access to health services in these smaller communities is often limited, and is further compounded by difficulties associated with the recruitment and retention of health practitioners. ${ }^{6}$

The context of rural practice, and the capacity to develop services within a specific rural or remote region, is influenced by historical and local circumstances. Nonetheless, the size and location of a rural or remote community are the main determinants of the range of resident health professionals and services being delivered locally. Population can be viewed as a proxy for availability of services, such as health and education, where government has a role in provision, funding or planning. ${ }^{7}$ Also, proximity to, or remoteness from, other larger centres influences the accessibility of other services.

The majority of Australians have access to wellresourced urban centres where effective primary health care tends to be taken for granted and the emphasis is on secondary and tertiary levels of service. By 
contrast, the focus in rural areas is for meeting basic health needs and demands, and for constructing an adequate provision of primary health care supported by transferral arrangements to centres with higher level services. The extent of the challenge for capacity building in remote Aboriginal communities can be illustrated by what several experienced health professionals in remote areas regard as a set of core activities that are required for the delivery of comprehensive primary health care services: ${ }^{8}$

- 24-hour emergency care;

- immunisation;

- a specific program for child health;

- antenatal care;

- a prevention and control program for sexually transmissible and HIV infections;

- referral and evaluation system;

- chronic disease surveillance and treatment;

- health worker training and support programs;

- systematic approaches to staff recruitment, orientation, support and career development;

- data collection on population, interventions and outcomes;

- evaluation of activities;

- targeted and evaluated programs to manage, reduce and prevent substance abuse.

Another set of core environmental health activities has been recommended for maintaining healthy living conditions in remote communities. It all amounts to a huge task for relatively sparse workforces operating across wide areas and consisting of medical clinicians, nurses and Aboriginal health workers; with support from public health and allied health workers, social workers and community mental health workers.

This is where the operational specifics of capacity building become so important, starting with the definition of precise program goals and objectives that constitute the basis for agreed-upon protocols for clinical care and public health system management. Then follows the creation of essential linkages, networks, multiskilling of health workers and other process requirements for focused primary health care delivery that makes optimal use of available resources. Competent and professional management is, of course, essential for program development, implementation and service delivery.

Until recently, the lack of accessible and relevant education and vocational training had long been a major concern for health professionals considering taking up rural practice, and for those already in rural practice. During the 1990s, improved regional access to education and training was established through a network of Rural Health Training Units. ${ }^{9}$ These initial units operated on discipline-specific lines with a strong emphasis on training rural general practitioners. Subsequent units were required to provide multi-disciplinary training under a single management structure. Some units took a further step by forming inter-disciplinary teams to provide education to different professional groups using an integrated educational curriculum. ${ }^{10}$

The location of rural health training units in major regional centres in all states and the Northern Territory still left a number of rural and remote regions without easy access to the new educational infrastructure formed as part of this initiative. The establishment of a training unit at Broken Hill in 1995, and the subsequent unveiling of a Commonwealth government funded program to develop a network of academic Departments of Rural Health and Rural Clinical Schools represented the next phase of building educational capacity in both rural and remote areas.

For the first time both rural and remote regional centres were being targeted for development. ${ }^{11}$ These academic units were to be responsible for ensuring that health professionals in defined regions, including those residing in the smaller settlements, have access to the new educational and support services. These services include

- library and health information facilities

- traditional academic teaching at the undergraduate and postgraduate level

- support for vocational education and ongoing professional development.

The latter role will link with the existing educational service providers to facilitate the integration of educational effort from undergraduate to vocational training and ongoing professional development.

Advances with information technology have obvious implications for capacity building especially with the development of new linkages and networked activities. Sustained utilisation depends, however, on the capabilities of rural and remote telecommunications infrastructure, and on the willingness of governments to maintain effective systems of information technology.

Another prospect for the new rural academic units is to provide on-site bases for research, particularly on the specific health needs of rural communities and the effectiveness of interventions and the resources in the different regions. Introduction of rural research capabilities will facilitate an important aspect of rural health capacity building, which is to identify such matters as how best to sustain an effective interventional program or to measure the result of efforts to engage a community's willingness to participate in a health improvement strategy. 
The capacity of the rural sector is being enhanced through these educational initiatives. It reflects on a general point that where significant gaps exist in education or professional services and support, investment may be required to create new facilities, services and relationships that provide support to rural practitioners. Thus, university departments of rural health-as new infrastructure-fill a gap by attracting experienced academics to work in the bush, and through those institutions provide educational opportunities and support to rural practitioners that were not previously available.

The capacity for rural health is increased when effective collaboration occurs among individuals and organisations to provide new or enhanced services. In fact, progress with capacity building in rural health will depend on encouraging a strong level of participation among rural health workers to look beyond the limits of their established activities and to engage in constructive discussion on improving capacity. In rural areas this has the potential to combine local expertise and networks to achieve greater capacity, self-reliance and sustainability of effort. Both commonwealth and state government incentives and funding have been successful in forging collaborative ventures in local communities (for example: multipurpose services such as is planned for communities like Collarenebri, Lightning Ridge, Brewarrina, and Wilcannia in far western NSW) and at the regional level, as indicated by the recent move to establish regional models of general practice training.

In the broader context, greater regional capacity-and collaboration among rural practitioners and organisations-will enable the rural areas to become more effective in defining and then negotiating the support they require from outside the region. These links are now resulting in strategic alliances between some rural and metropolitan based health services to provide specialist outreach and referral services (such as the eye program in Bourke between the Far West Area Health Service and the Prince of Wales Hospital in Sydney). Regional units of major institutions such as university departments of rural health are also joining with their academic colleagues on main campus to establish new educational courses for rural practitioners. For those providing services and support from a non-rural setting, there is the opportunity to develop a greater awareness, understanding, and regard for the work of rural practitioners.

The three pillars of the public health system are:

- service delivery

- teaching

- research.
In rural areas the capacity to carry out all three of these functions has been limited due to inadequate regional infrastructure and human resources. While it is too early to determine what will be achieved with the most recent investment in rural education and training, when considered alongside other investments aimed at building capacity in service delivery and research, it should be the cause for greater optimism about the future of rural health.

\section{REFERENCES}

1. Hawe P, King L, Noort M, Gifford SM, Lloyd B, Working invisibly: health workers talk about capacity building in health promotion. Health Promotion International 1998; 13: 285295.

2. Building Capacity for Public Health. NSW Public Health Bulletin 2000; 11: 21-34.

3. A Capacity Building Web Site. NSW Public Health Bulletin 2000; 11:123. www.health.nsw.gov.au/public-health/ healthpromotion.

4. Australian Health Ministers' Conference. National Rural Health Strategy 1994. Canberra: Australian Government Publishing Service, 1994.

5. Australian Institute of Health and Welfare. Health in rural and remote Australia. Canberra: AIHW, 1998. AIHW Catalogue no. PHE6.

6. Best J. Rural Health Stocktake. Canberra: Commonwealth of Australia, 2000.

7. Information and Research Branch (Commonwealth Department of Health and Aged Care) and the National Centre for Social Applications of Geographical Information Systems (University of Adelaide). Measuring Remoteness: Accessibility-Remoteness Index of Australia (ARIA). Canberra: Commonwealth of Australia, 1999.

8. Flick B, Miller P, Torzillo P, Wilson J. Aboriginal health services delivery in remote Australia. Issues Facing Australian Families. Weeks W and Quinn M (editors). Melbourne: Longmans, 2000; 343-359.

9. Australian Health Ministers Advisory Council. A National Framework for Education and Training Arrangements for Rural Health Services. Canberra: Commonwealth Department of Health and Aged Care, 1995.

10. Cox V. Final Report-Implementing the resolution of recommendations from the National Association of Rural Health Training Units Workshop. Canberra: Department of Health and Aged Care, 1996.

11. Humphreys J, Lyle D, Wakerman J, Chalmers E, Wilkinson D, Walker J, Simmons D, Larson A. The Roles and Activities of the Commonwealth Government University Departments of Rural Health. Aust J Rural Health 2000; 8: 120-133. F 